\title{
The power options for transmitting systems using thermal energy generator
}

\author{
Michal Oplustil \\ Department of Automation and Control Engineering \\ Tomas Bata University in Zlin \\ Zlin, Czech Republic \\ oplustil@fai.utb.cz
}

\author{
Martin Zalesak \\ Department of Automation and Control Engineering \\ Tomas Bata University in Zlin \\ Zlin, Czech Republic \\ zalesak@fai.utb.cz
}

\begin{abstract}
This paper was aimed on system design of electric energy converting from thermal energy. This electric energy was harvested by human actions or from human impact on the device. The first part of this article describes principles of thermal energy conversion to electric energy. The second part of this paper describes design of the thermoelectric generator for the autonomous broadcast systems.
\end{abstract}

Keywords-thermal energy Seebeck effect; Peltier module; thermoelectric generator; thermoelectric cooler; step-up DC/DC converter

\section{PROBLEM FORMULATION}

There are very popular wireless controllers application in wide field of the control technology at present. As other electrical devices, wireless transmitting elements need some amount of the electrical energy to run. The most common way for powering of autonomous wireless transmitting systems is by utilization of batteries or accumulators. These energy sources are of short time means type and require frequent replacements and in some cases their utilization is not applicable at all.

There are some other means available at present, which enable generation of necessary electric power by the human action so called human action energy harvesting systems. The most common ways for electric energy generation are those of using electromagnetic, piezoelectric or thermoelectric principles. This paper deals with a possible way of utilization of the thermoelectric generator (TEG) for the application in the wireless control systems in buildings, with energy supply by human palms. Specific problems in this application is the way of required power generation from the source of small temperature difference. The aim of this article is introduce the numerator using thermoelectric generator as a power source for wireless transmitting systems.

The design of the transmitter could be divided in parts as the thermoelectric generator (TEG), electrical transformer and wireless signal generator. There are described TEG and electrical transformer in this article.

\section{FUNDAMENTALS}

\section{A. Starting points}

The thermoelectric power source is based on Peltier's cells, which could generate electric power by heat. But using only Peltier's cells without any supporting device is inadequate, because output voltage is only few tens to hundred milivolts, based on the temperature difference and density of thermoelectric junctions. Temperature difference depends on human physiology (palm temperature) and surrounding air temperature. It is roughly in few centigrade, while density of thermoelectric connections is purely technology mean. It means that the solution of the task is only technology matter. But even technology solution is limited by the acceptable size of the transmitter. So the limits for the design and construction of transmitter generated by the heat of human palms are temperature of the palm, (warmer junction), temperature of the surrounding air (cold junction), parameters needed by RF transmitter and the acceptable size of the transmitter.

\section{B. Thermoelectric effect analyses}

The thermoelectric effect of the Peltier's module could be described by the (1) and (2)

$$
\begin{aligned}
& \vec{i}=\sigma_{T} \cdot(\vec{E}-\alpha \cdot \vec{\nabla} T) \\
& \vec{q}=\alpha \cdot \vec{i} \cdot \Delta T-\lambda \cdot \vec{\nabla} T
\end{aligned}
$$

Where:

$i$ is density of electric current, in $\mathrm{A} / \mathrm{m}^{2}$;

$E$ electric field, in $\mathrm{W} / \mathrm{m}$;

$q$ heat flow density, in $\mathrm{W} / \mathrm{m}^{2}$;

$\nabla T$ temperature gradient in $\mathrm{K}$;

$\sigma_{T}$ electric conduction, in $\mathrm{S}$; 
$\alpha$ Seebeck coefficient, in $\mathrm{V} /(\mathrm{m} . \mathrm{K})$;

$\lambda$ thermal conductivity of thermocouple wire measured at $E=0$, in $\mathrm{W} /(\mathrm{m} . \mathrm{K})$;

$\Delta T$ temperature difference of the junctions, in $\mathrm{K}$;

The output power of the thermoelectric generator in case of no load, $U_{0}$, could be described as follows:

$$
U_{0}=\bar{\alpha} \cdot \Delta T
$$

Where:

$U_{0}$ is output voltage from generator, in $\mathrm{V}$;

$\bar{\alpha}$ average Seebeck coefficient, in $\mathrm{V} / \mathrm{K}$;

$\Delta T$ temperature difference across the junction in $\mathrm{K}$. Where

$$
\Delta T=T_{h}-T_{c}
$$

$T_{h}$ temperature of the warmer junctions, in $\mathrm{K}$;

$T_{c}$ temperature of the colder junctions, in $\mathrm{K}$.

If a load is connected to the output of the thermoelectric generator, voltage drops as a result of an internal generator resistance and of the load. The current in the load circuits, $I$, could be expressed as follows:

$$
I=\frac{U_{0}}{R_{c}+R_{l}}
$$

Where:

$I$ is output current of the generator in load circuits, in A;

$U_{0}$ see (3);

$R_{c}$ internal resistance of the generator, in $\Omega$;

$R_{l}$ the load circuit resistance, in $\Omega$.

The total heat input to the thermoelectric junction, $P_{h}$, is defined as follows from (1) and (2):

$$
P_{h}=S \cdot\left(\alpha \cdot \Delta T \cdot I-0,5 \cdot I^{2} \cdot R_{c}+\frac{\lambda}{l} \cdot \Delta T\right)
$$

Where:

$P_{h}$ is thermal power entering to the generator, in $\mathrm{W}$;

$S$ area of the junction, in $\mathrm{m}^{2}$;

$l$ distance between thermocouple junctions, in $\mathrm{m}$;

$\alpha, T_{h}, I, R_{c}, \lambda, \Delta T$ for explanation see above.

The efficiency of the thermal generator, $E_{g}$, could be expressed as:

$$
E_{g}=\frac{U_{0} \cdot I}{P_{h}}
$$

The thermoelectric module consists of number of junctions:

$$
U_{0}=\overline{\alpha_{M}} \cdot \Delta T \cdot\left(R_{M} \cdot R_{l}\right)
$$

Where:

$U_{0}$ is generator voltage output, in $\mathrm{V}$;

$\alpha_{M}$ module's average Seebeck coefficient, in $\mathrm{V} / \mathrm{K}$;

$R_{M}$ module's average resistance, in $\Omega$;

$R_{l}$ load circuit resistance, in $\Omega$.

The Seebeck coefficient, $\alpha_{M}$, resistance, $R_{M}$, and thermal conductivity, $\lambda$, are temperature depend and their values must be calculated case to case, otherwise, the values could be selected based on the average temperature of the module, $T_{\text {avg }}$ where:

$$
T_{\text {avg }}=\frac{T_{h}+T_{c}}{2}
$$

\section{PROBLEM SOLUTION}

\section{A. Device description}

The thermoelectric generator (TEG) is composed of high density of P-N metallic junctions (telur - bismuth) between two ceramic plates. One of the plates represents the warm side of TEG and the other forms the cold one. The junctions are formed from several P-N metallic couples shaped orthogonally. The schematic of the TEG shows Fig.1.

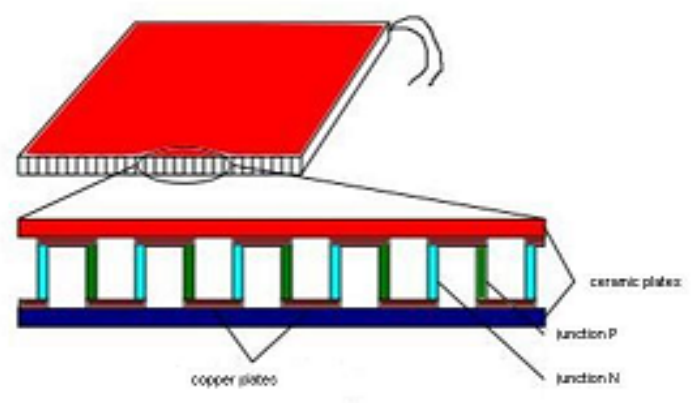

Fig. 1. Section of Peltier's cell.

The output power from the module which contents of $N T$ number of junctions, $\mathrm{P}_{\mathrm{o}}$ could be expressed as follows:

$$
P_{0}=U_{0} \cdot I=\frac{N T \cdot\left(\alpha_{M} \cdot \Delta T\right)^{2}}{4 \cdot R_{M}}
$$


Problem is, that the heat flowing from the warm side to the cold side of the TEG increases temperature of the cold side and thus decrease, the temperature difference, $\Delta \mathrm{T}$, and farther decrease the output power of thermocouples, $\mathrm{P}_{\mathrm{o}}$. That is why it is necessary to transfer the heat flowing from the warm side to the cold side of TEG as much to the surrounding area - it means to decrease the thermal resistance of the part of the TEG between the cold plate and the outside colder surface of the TEG and farther from the outside surface to the surrounded environment (air, in case of hand control transmitter or wall, in wall mounted transmitter). Heat flow transferred to the cold side of the TEG by the heat conduction via thermocouples from the warm side, $\mathrm{P}_{\mathrm{c}}$ is given.

$$
P_{c}=\left(0,5 \cdot I^{2} \cdot R_{C}+\frac{\lambda}{l} \cdot \Delta T\right)
$$

And heat flow density, $q_{c}$ is defined as:

$$
q_{c}=\frac{P_{c}}{A_{c}}
$$

In relations (11) and (12) stand for

$P_{c}$ is heat flow, in $\mathrm{W}$;

$A_{c}$ area of the TEG cold side surface, in $\mathrm{m}^{2}$.

The maximum allowable thermal resistance, $R_{T}$, of the TEG between cold plate and the surrounded air:

$$
R_{T}=\frac{\Delta T_{\text {rise }}}{q_{c}}
$$

Where:

$R_{T}$ is allowed thermal resistance, in $\left(\mathrm{m}^{2} . \mathrm{K} / \mathrm{W}\right)$;

$\Delta T_{\text {rise }}$ maximal allowed cold junction temperature increment, in ${ }^{\circ} \mathrm{C}$;

$q_{c}$ heat flow density see (12).

According to analyses of the measured data we have found that the output voltage of the relevant TEG are in ranges of tens (TEC1) or hundreds maximally of milivolts (TEC2). This is too low voltage level for power to other devices. It results to the fact, that the TEG could not be used directly, but it requires some means of transfer the output level voltage to higher one. There exists more possibilities how to achieve higher output voltage levels. The simplest way is connect the output of TEG to input of a conversion transformer with a suitably chosen transformation ratio and appropriate resistance of primary windings. But this way would disproportionately load of the TEG. Another way to increase the output voltage level of the generator is to use DC/DC converter. Whereby is possible to achieve an increase in output voltage at the units of volts. This voltage level will be already sufficient to power the connected equipment. Fig.2. described supposed method of adjusting of output voltage.

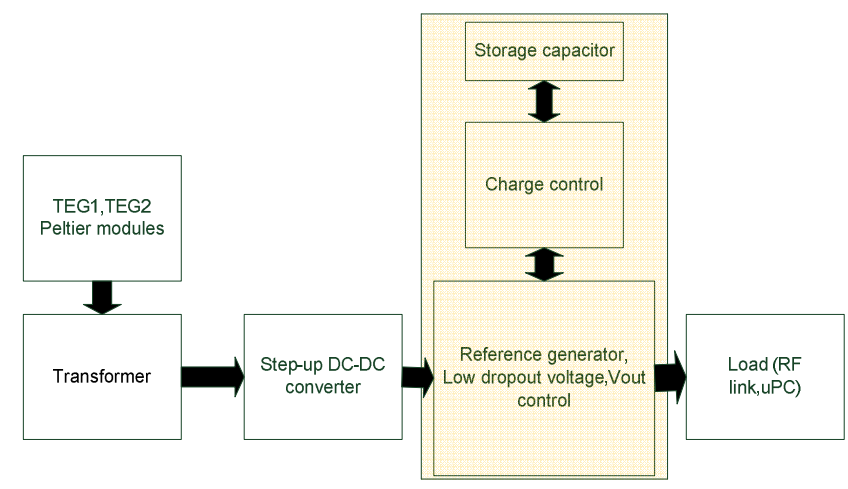

Fig. 2. Block diagram of the generator

Mechanical construction of device is simple. An input part of the device is formed by Peltier's module (TEC1, TEC2). Voltage output from the Peltier's module is connected to a primary winding of a transformer with transformation ratio in this case 1:100. Secondary winding of this transformer is connected to first part of step-up DC-DC converter. This first part of this block is synchronous rectifier, second part is composed of shunt voltage regulator. Output voltage of this regulator is used for supply other block of device. Next step of voltage modification is Power manager which consists of reference generator, low dropout voltage, Vout controller, charge control and storage capacitor. For the level of voltage control is used an ultra low voltage step-up converter and a power manager consisted of LTC 3108-1 from Linear Technology and five supported components. This device operates from inputs of $20 \mathrm{mV}$ which is suitable for our application. The converter powers a wireless transmission element normaly used in building control systems. Based an above stated requirements the device is larger than $u$ wall switch usually used. Whole device is situated on the one side PCB with dimensions of $55 \times 28 \mathrm{~mm}$. Table 1. described parameters of Peltier's modules.

TABLE I. TEG PARAMETERS

\begin{tabular}{|c|c|c|c|c|c|c|c|}
\hline Type & $\begin{array}{c}\boldsymbol{I}_{\max } \\
{[\mathrm{A}]}\end{array}$ & $\begin{array}{c}\Delta \boldsymbol{T}_{\max } \\
{[\mathrm{K}]}\end{array}$ & $\begin{array}{c}\boldsymbol{U} \\
{[\mathrm{V}]}\end{array}$ & $\begin{array}{c}\boldsymbol{P}_{\max } \\
{[\mathrm{W}]}\end{array}$ & $\begin{array}{c}\boldsymbol{L} \\
{[\mathrm{mm}]}\end{array}$ & $\begin{array}{c}\boldsymbol{B} \\
{[\mathrm{mm}]}\end{array}$ & $\begin{array}{c}\boldsymbol{H} \\
{[\mathrm{mm}]}\end{array}$ \\
\hline TEC1 & $\mathbf{8 . 5}$ & $\mathbf{6 8}$ & $\mathbf{2 . 0 6}$ & $\mathbf{9 . 2}$ & $\mathbf{1 5}$ & $\mathbf{1 5}$ & $\mathbf{3 . 3}$ \\
\hline TEC2 & $\mathbf{8 . 5}$ & $\mathbf{6 8}$ & $\mathbf{1 5 . 4}$ & $\mathbf{8 1}$ & $\mathbf{5 0}$ & $\mathbf{5 0}$ & $\mathbf{4 . 5}$ \\
\hline
\end{tabular}

With wall mounted cold side of the Peltier's module it is possible to obtain temperature difference between the human palm and a wall surface approx. $\Delta T=11^{\circ} \mathrm{C}$. This temperature difference represents output voltage of $35 \mathrm{mV}$ with TEC1and $150 \mathrm{mV}$ with TEC2 Peltier module.

Fig.3.Shown schematic diagram of used DC/DC converter. 


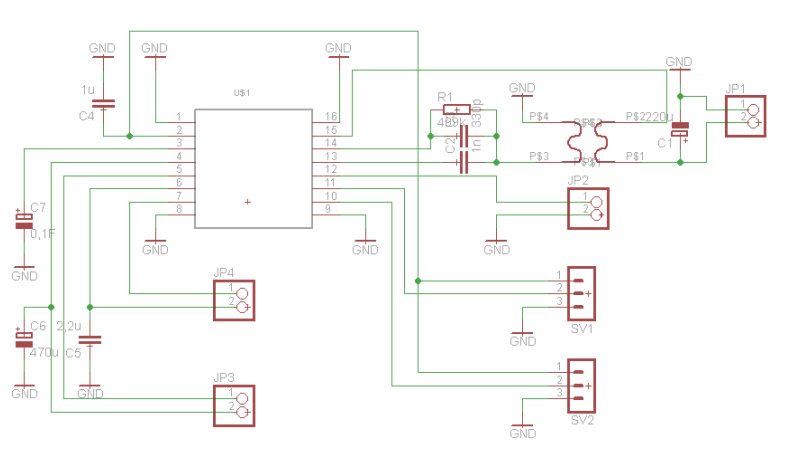

Fig. 3. DC/DC converter schematic

Theoretical maximum power output from the used Peltier modules TEC1 and TEC2 could be calculated from (10):

$$
\begin{aligned}
& P_{0, \max 1}=\frac{\left(\alpha_{M} \cdot \Delta T\right)^{2}}{4 \cdot R_{M}}=\frac{(0,01257 \cdot 11)^{2}}{4 \cdot 0,364}=0,013 \mathrm{~W} \\
& P_{0, \max 2}=\frac{\left(\alpha_{M} \cdot \Delta T\right)^{2}}{4 \cdot R_{M}}=\frac{(0,05150 \cdot 11)^{2}}{4 \cdot 3.350}=0,023 \mathrm{~W}
\end{aligned}
$$

This voltage output could meet requirements to power lowpower broadcasting systems.

Fig.4. shows step response of voltage output of the module. Fig 5. shows the dimensions of the unit.

Used step-up converter also includes regulated output voltage in range of $2,5 \mathrm{~V} ; 3 \mathrm{~V} ; 3,7 \mathrm{~V}$ and $4,5 \mathrm{~V}$. The level of output voltage can be changed by connecting pins VS1 and VS2 to $\mathrm{V}_{\mathrm{AUX}}$ or GND. Device was tested with all options of output voltage. In the application as a transmitter for building control systems voltage level $3 \mathrm{~V}, 3,7 \mathrm{~V}$ and $4,5 \mathrm{~V}$ could be used. Voltage level depends on required supply voltage of the transmitter.

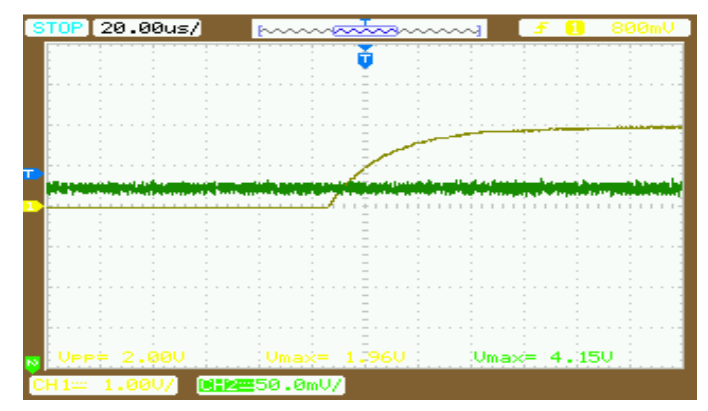

Fig. 4. $P G D$ and $V_{\text {out }}$ sequencing

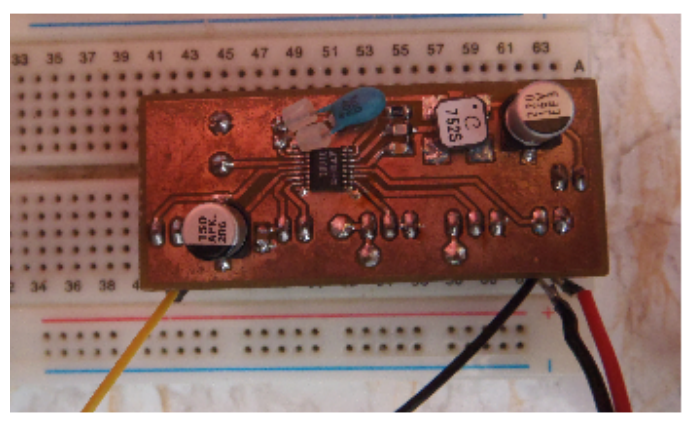

Fig.5. Test device

\section{CONCLUSION}

This paper describes the construction of the electric generator for wireless transmission systems. The main obstacle to the use of these electric generators is that, in this way we use a relatively small value of the temperature difference, $\Delta \mathrm{T}$, which depends on the human palm temperature and a wall surface temperature. From a measured data shows that. Even with the small temperature difference it enables to get enough electric energy for wireless transmitting in buildings control systems. Thermal generator described above has been designed to be able to supply current of $40 \mathrm{~mA}$ for the time of $1 \mathrm{~ms}$. This time is sufficient enough to transmit a simple telegram. The future work will deal with design of LonWorks telegram wireless transmission system with the application of thermoelectric generator as described in this paper.

\section{ACKNOWLEDGMENT}

At first of all, I would like to thank my colleagues from the office for quite working environment. This paper has arisen in the frame of Internal Grant Agency of Tomas Bata University in Zlin, Faculty of Applied Informatics IGA/FAI2013/026 and under the project CEBIA-TECH NO. CZ.1.05/2.1.00/03.

\section{REFERENCES}

[1] D. Guyomar, Y. Jayet, L. Petit, E. Lefeuvre, T. Monnier, C. Richard, M. Lallard, "Synchronized switch harvesting applied to self- powered smart systems: piezoactive microgenerators for autonomous wireless transmitters, Sensors and Actuators A:Phys, Vol.138, No.1, 2007, pp. 151-160.

[2] E. Lefeuvre, A. Badel, C. Richard, D. Guyomar, "A comparison between several vibration powered piezoelectric generators for stand alone systems, Sensors and Actuators A, Vol.126, No.2, 2006 , pp. 406416.

[3] Y. Deng, W. Zhu, Y. Wang, Y. Shi, "Enhanced performance of solar driven photovoltaic- thermoelectric hybrid system in an integrated design, Solar energy, Vol. 88, 2013, pp. 182-191.

[4] D.T. Crane, J.W. Lagrandeur, F. Harris, L.E. Bell, "Performance results of high-power-density thermoelectric generator: Beyond the couple, Journal of Electronic Materials, Vol.38, No.7, 2009, pp. 1376-1381.

[5] A.Z. Sahin, B.S. Yilbas, "Thermodynamic irreversibility and performance characteristic of thermoelectric power generator, Energy, Vol 55, 2013, pp 899-904.

[6] X. Gou, S. Yang, H. Xiao, Q. Ou, "A dynamic model for a thermoelectric generator applied in waste heat recovery, Energy, Vol. 52, 2013, pp 201-209.

[7] J.C. Moreno, E. Rodrigues, J. Frias, G. Esnal, Z. Liznam, K. Vouros, "Energy sources manager in buildings: Control and monitoring, Proceeding of the 3rd international conference on Circuits, Systems, Control, Signals (CSCS 2012), pp. 15-21.

[8] Linear Technology, LTC 3108 datasheet, available online: http://cds.linear.com/docs/en/datasheet/3108fb.pdf.

[9] ZT Service Inc. C.B.Vining, The thermoelectric Process, available online: http://www.poweredbythermolife.com/research.htm

[10] Ferro Tec, Thermoelectric Technical Reference, available online: http://thermal.ferrotec.com/technology/thermoelectric/thermalRef01/

\section{Creative Commons Attribution License 4.0} (Attribution 4.0 International, CC BY 4.0)

This article is published under the terms of the Creative Commons Attribution License 4.0 https://creativecommons.org/licenses/by/4.0/deed.en_US 